\title{
Numerical Simulation Analysis on Displacement Response of Frame Structure and Shear Wall Structure Under the Action of Wind Load
}

\author{
Yang Lujiang ${ }^{1, a}$, Chen Gong ${ }^{\star 1,2, b}$ and Yang Hongmei ${ }^{1, c}$ \\ ${ }^{1}$ Chengdu Textile College, Chengdu, China, 611731 \\ ${ }^{2}$ Chengdu University of Technology, Chengdu, China, 610059 \\ a724422011@qq.com, b114032216@qq.com, '33205524@qq.com
}

\begin{abstract}
Keywords: frame structure, shear wall structure, numerical simulation analysis, displacement response, compare and analyze

Abstract: Response of earthquake action in the structure is related to site category, seismic fortification intensity, earthquake acceleration, seismic grouping, etc. Research on high-rise building structure seismic has been done a lot. However, high-rise building structure does not only sustain earthquake load, but also sustain wind load, which is calculation and analysis of wind-resistant behavior of structure. Response of wind load in the structure is related to wind pressure, ground roughness, vertical wind acceleration, lateral wind acceleration, shape coefficient of each section in the structure. Research is based on stress characteristic of frame structure and shear wall structure. Firstly, stress characteristic of structure under the action of wind load has been simulated. Secondly, displacement response of structure under the action of wind load has been calculated by numerical simulation software "PKPM", also displacement response of frame structure and shear wall structure under the action of wind load has been reached. Thirdly, the displacement response of structure has been compared and analyzed. Finally the conclusions are made.
\end{abstract}

\section{Introduction}

Response of earthquake action in the structure is related to site category, seismic fortification intensity, earthquake acceleration, seismic grouping, etc. Research on high-rise building structure seismic has been done a lot. However, high-rise building structure does not only sustain earthquake load, but also sustain wind load, which is calculation and analysis of wind-resistant behavior of structure. Response of wind load in the structure is related to wind pressure, ground roughness, vertical wind acceleration, lateral wind acceleration, shape coefficient of each section in the structure. Research is based on stress characteristic of frame structure and shear wall structure.

\section{Establishment of Structure Technical Parameter}

The modeling parameters of the computer simulation building model are as follows. The building structure is office building with single aisle, where is set with light sound insulation wall. The openings of shear wall and weight of partition wall are not considered. Standard value of permanent load is $3.5 \mathrm{KN} / \mathrm{m}^{2}$. According to load code for the design of building structures(GB 50009-2012), standard value of variable load is $2.0 \mathrm{KN} / \mathrm{m}^{2}$. Corrected basic wind pressure is $0.1 \mathrm{KN} / \mathrm{m}^{2}$, and ground roughness is type A. Considering vertical wind load vibration, shape coefficient of each section in the structure is 1.3. Space of vertical grid is $5 \mathrm{~m} \times 10$, and space of horizontal grid is $5 \mathrm{~m}+2.5 \mathrm{~m}+5 \mathrm{~m}$, layer height is $3 \mathrm{~m}$. In the frame structure, section size of column is $500 \mathrm{~mm} \times 500 \mathrm{~mm}$, section size of beam is $300 \mathrm{~mm} \times 550 \mathrm{~mm}$ and $250 \mathrm{~mm} \times 500 \mathrm{~mm}$. In the shear wall structure, thickness of shear wall is $500 \mathrm{~mm}$ which is set along the lateral grid, also section size of connecting beam is $300 \mathrm{~mm} \times 550 \mathrm{~mm}$, $250 \mathrm{~mm} \times 500 \mathrm{~mm}$. Thickness of floor in the structure is $120 \mathrm{~mm}$. According to code for design of concrete structures(GB 50010 - 2010), strength level of concrete of frame column, frame beam, shear wall and connecting beam is C40. Strength level of concrete of casting floor is C30. Type of vertical stressed steel bar in the frame column, frame beam, shear wall, connecting beam and casting floor is 
HRB400, type of stirrups is HPB300. 10-storeys frame structure is model 1, and 10-storeys shear wall structure is model 2.

\section{Numerical Simulation Results}

Maximum displacement of the floor in the structure under wind load is shown by table 1, table 2, table 3 and table 4. Comparative analysis of comfortable in model 1 and model 2 under wind load is shown by table 5. In table 1, table 2, table 3, table 4, Max-(X) and Max-(Y) are Maximum displacement of node in the $\mathrm{X}$ direction and $\mathrm{Y}$ direction, Max-Dx and Max-Dy are maximum interlayer displacement of floor in the $\mathrm{X}$ direction and $\mathrm{Y}$ direction, Ave-(X) and Ave-(Y) are average displacement of floor in the $\mathrm{X}$ direction and $\mathrm{Y}$ direction, Ave-Dx and Ave-Dy are average interlayer displacement of floor in the $\mathrm{X}$ direction and $\mathrm{Y}$ direction, Ratio- $(\mathrm{X})$ and Ratio- $(\mathrm{Y})$ are the ratio of the maximum displacement to the average displacement of the layers in the $\mathrm{X}$ direction and $\mathrm{Y}$ direction, Ratio-Dx and Ratio-Dy are are the ratio of the maximum interlayer displacement to the average interlayer displacement of the layers in the $\mathrm{X}$ direction and $\mathrm{Y}$ direction, Max-Dx/h and Max-Dy/h are maximum interlayer displacement angle of the layers in the $\mathrm{X}$ direction and $\mathrm{Y}$ direction, DxR/Dx and DyR/Dy are percentage of the total displacement angle of the harmful displacement angle of the layers in the $\mathrm{X}$ direction and $\mathrm{Y}$ direction, Ratio-AX and Ratio-AY are the maximum of displacement angle of the layer, 1.3 times of the upper displacement angle, 1.2 times of upper three layer mean shift angle in the $\mathrm{X}$ direction and $\mathrm{Y}$ direction. In addition to dimensionless measures, the measure of every displacement is $\mathrm{mm}$.

Table 1 Maximum displacement of the floor in model 1 under wind load ( $X$ direction)

\begin{tabular}{cccccccccc}
\hline Floor & Max-(X) & Max-Dx & Ave-(X) & Ave-Dx & Ratio-(X) & Ratio-Dx & Max-Dx/h & DxR/Dx & Ratio-AX \\
\hline 10 & 0.43 & 0.01 & 0.43 & 0.01 & 1.00 & 1.00 & $1 / 9999$ & $76.7 \%$ & 1.00 \\
9 & 0.42 & 0.02 & 0.42 & 0.02 & 1.00 & 1.00 & $1 / 9999$ & $42.6 \%$ & 1.36 \\
8 & 0.40 & 0.03 & 0.40 & 0.03 & 1.00 & 1.00 & $1 / 9999$ & $28.1 \%$ & 1.52 \\
7 & 0.37 & 0.04 & 0.37 & 0.04 & 1.00 & 1.00 & $1 / 9999$ & $20.5 \%$ & 1.53 \\
6 & 0.33 & 0.04 & 0.33 & 0.04 & 1.00 & 1.00 & $1 / 9999$ & $15.7 \%$ & 1.29 \\
5 & 0.29 & 0.05 & 0.29 & 0.05 & 1.00 & 1.00 & $1 / 9999$ & $12.3 \%$ & 1.17 \\
4 & 0.23 & 0.06 & 0.23 & 0.06 & 1.00 & 1.00 & $1 / 9999$ & $9.5 \%$ & 1.09 \\
3 & 0.18 & 0.06 & 0.18 & 0.06 & 1.00 & 1.00 & $1 / 9999$ & $4.5 \%$ & 1.03 \\
2 & 0.11 & 0.07 & 0.11 & 0.07 & 1.00 & 1.00 & $1 / 9999$ & $25.7 \%$ & 0.96 \\
1 & 0.05 & 0.05 & 0.05 & 0.05 & 1.00 & 1.00 & $1 / 9999$ & $99.9 \%$ & 0.66 \\
\hline
\end{tabular}

Table 2 Maximum displacement of the floor in model 1 under wind load (Y direction)

\begin{tabular}{cccccccccc}
\hline Floor & Max-(Y) & Max-Dy & Ave-(Y) & Ave-Dy & Ratio-(Y) & Ratio-Dy & Max-Dy/h & DyR/Dy & Ratio-AY \\
\hline 10 & 1.99 & 0.07 & 1.99 & 0.07 & 1.00 & 1.00 & $1 / 9999$ & $50.3 \%$ & 1.00 \\
9 & 1.92 & 0.11 & 1.92 & 0.11 & 1.00 & 1.00 & $1 / 9999$ & $32.6 \%$ & 1.16 \\
8 & 1.81 & 0.15 & 1.81 & 0.15 & 1.00 & 1.00 & $1 / 9999$ & $22.9 \%$ & 1.33 \\
7 & 1.66 & 0.18 & 1.66 & 0.18 & 1.00 & 1.00 & $1 / 9999$ & $17.1 \%$ & 1.36 \\
6 & 1.48 & 0.21 & 1.48 & 0.21 & 1.00 & 1.00 & $1 / 9999$ & $13.2 \%$ & 1.21 \\
5 & 1.27 & 0.24 & 1.27 & 0.24 & 1.00 & 1.00 & $1 / 9999$ & $10.2 \%$ & 1.11 \\
4 & 1.04 & 0.26 & 1.04 & 0.26 & 1.00 & 1.00 & $1 / 9999$ & $7.4 \%$ & 1.04 \\
3 & 0.77 & 0.28 & 0.77 & 0.28 & 1.00 & 1.00 & $1 / 9999$ & $2.1 \%$ & 0.99 \\
2 & 0.49 & 0.29 & 0.49 & 0.29 & 1.00 & 1.00 & $1 / 9999$ & $29.0 \%$ & 0.92 \\
1 & 0.20 & 0.20 & 0.20 & 0.20 & 1.00 & 1.00 & $1 / 9999$ & $99.9 \%$ & 0.61 \\
\hline
\end{tabular}


Table 3 Maximum displacement of the floor in model 2 under wind load (X direction)

\begin{tabular}{cccccccccc}
\hline Floor & Max-(X) & Max-Dx & Ave-(X) & Ave-Dx & Ratio-(X) & Ratio-Dx & Max-Dx/h & DxR/Dx & Ratio-AX \\
\hline 10 & 0.40 & 0.02 & 0.40 & 0.02 & 1.00 & 1.00 & $1 / 9999$ & $36.6 \%$ & 1.00 \\
9 & 0.38 & 0.02 & 0.38 & 0.02 & 1.00 & 1.00 & $1 / 9999$ & $34.4 \%$ & 1.05 \\
8 & 0.36 & 0.03 & 0.36 & 0.03 & 1.00 & 1.00 & $1 / 9999$ & $26.5 \%$ & 1.29 \\
7 & 0.33 & 0.04 & 0.33 & 0.04 & 1.00 & 1.00 & $1 / 9999$ & $19.9 \%$ & 1.38 \\
6 & 0.29 & 0.05 & 0.29 & 0.05 & 1.00 & 1.00 & $1 / 9999$ & $14.6 \%$ & 1.26 \\
5 & 0.24 & 0.05 & 0.24 & 0.05 & 1.00 & 1.00 & $1 / 9999$ & $9.3 \%$ & 1.15 \\
4 & 0.19 & 0.06 & 0.19 & 0.06 & 1.00 & 1.00 & $1 / 9999$ & $2.2 \%$ & 1.05 \\
3 & 0.14 & 0.06 & 0.14 & 0.06 & 1.00 & 1.00 & $1 / 9999$ & $11.7 \%$ & 0.94 \\
2 & 0.08 & 0.05 & 0.08 & 0.05 & 1.00 & 1.00 & $1 / 9999$ & $50.3 \%$ & 0.77 \\
1 & 0.03 & 0.03 & 0.03 & 0.03 & 1.00 & 1.00 & $1 / 9999$ & $99.9 \%$ & 0.38
\end{tabular}

Table 4 Maximum displacement of the floor in model 2 under wind load (Y direction)

\begin{tabular}{cccccccccc}
\hline Floor & Max-(Y) & Max-Dy & Ave-(Y) & Ave-Dy & Ratio-(Y) & Ratio-Dy & Max-Dy/h & DyR/Dy & Ratio-AY \\
\hline 10 & 0.21 & 0.02 & 0.21 & 0.02 & 1.00 & 1.00 & $1 / 9999$ & $3.3 \%$ & 1.00 \\
9 & 0.19 & 0.02 & 0.19 & 0.02 & 1.00 & 1.00 & $1 / 9999$ & $2.7 \%$ & 0.79 \\
8 & 0.16 & 0.03 & 0.16 & 0.03 & 1.00 & 1.00 & $1 / 9999$ & $1.6 \%$ & 0.87 \\
7 & 0.14 & 0.03 & 0.14 & 0.03 & 1.00 & 1.00 & $1 / 9999$ & $0.7 \%$ & 0.87 \\
6 & 0.11 & 0.03 & 0.11 & 0.03 & 1.00 & 1.00 & $1 / 9999$ & $3.9 \%$ & 0.84 \\
5 & 0.09 & 0.02 & 0.09 & 0.02 & 1.00 & 1.00 & $1 / 9999$ & $8.6 \%$ & 0.80 \\
4 & 0.06 & 0.02 & 0.06 & 0.02 & 1.00 & 1.00 & $1 / 9999$ & $15.6 \%$ & 0.74 \\
3 & 0.04 & 0.02 & 0.04 & 0.02 & 1.00 & 1.00 & $1 / 9999$ & $27.6 \%$ & 0.65 \\
2 & 0.02 & 0.01 & 0.02 & 0.01 & 1.00 & 1.00 & $1 / 9999$ & $54.1 \%$ & 0.56 \\
1 & 0.01 & 0.01 & 0.01 & 0.01 & 1.00 & 1.00 & $1 / 9999$ & $99.9 \%$ & 0.35 \\
\hline
\end{tabular}

Table 5 Comparative analysis of comfort of model 1 and model 2 under wind load

\begin{tabular}{cccccccccccc}
\hline \multirow{2}{*}{ Model } & $\begin{array}{c}\text { Direc } \\
\text { tion }\end{array}$ & $\begin{array}{c}\text { Pulsation } \\
\text { increasing } \\
\text { coefficient }\end{array}$ & $\begin{array}{c}\text { Pulsation } \\
\text { influencing } \\
\text { coefficient }\end{array}$ & $\begin{array}{c}\text { Body type } \\
\text { coefficient }\end{array}$ & $\begin{array}{c}\text { Reproductive } \\
\text { period } \\
\text { adjustment } \\
\text { factor }\end{array}$ & $\begin{array}{c}\text { Windward } \\
\text { area }\left(\mathrm{m}^{2}\right)\end{array}$ & $\begin{array}{c}\text { Wind } \\
\text { pressure } \\
(\mathrm{KPa})\end{array}$ & $\begin{array}{c}\text { Basic } \\
\text { cycle } \\
(\mathrm{s})\end{array}$ & $\begin{array}{c}\text { Downwind } \\
\text { acceleration } \\
\left(\mathrm{m} / \mathrm{s}^{2}\right)\end{array}$ & $\begin{array}{c}\text { Lateral wind } \\
\text { acceleration } \\
\left(\mathrm{m} / \mathrm{s}^{2}\right)\end{array}$ \\
\hline \multirow{2}{*}{ Model 1 } & X & 1.32 & 0.53 & 1.30 & 1.00 & 37.50 & 0.10 & 0.38 & $4.95 \mathrm{E}-03$ & $1.07 \mathrm{E}-03$ \\
& $\mathrm{Y}$ & 1.32 & 0.48 & 1.30 & 1.00 & 150.00 & 0.10 & 0.38 & $1.79 \mathrm{E}-02$ & $1.07 \mathrm{E}-03$ \\
Model 2 & $\mathrm{X}$ & 1.26 & 0.53 & 1.30 & 1.00 & 37.50 & 0.10 & 0.38 & $3.35 \mathrm{E}-03$ & $4.94 \mathrm{E}-04$ \\
& $\mathrm{Y}$ & 1.26 & 0.48 & 1.30 & 1.00 & 150.00 & 0.10 & 0.38 & $1.21 \mathrm{E}-02$ & $4.94 \mathrm{E}-04$ \\
\hline
\end{tabular}

\section{Analysis of Calculation Results}

In table 1 , table 2 , table 3 , table 4 , when model 1 and model 2 are sustaining wind load, the models are simplified to cantilever beams which are sustaining on the foundation to simulate the stress behavior, so $\operatorname{Max}-(\mathrm{X})$ and Max-(Y) are changing gradually larger with the increase of floors. However, model 2 is shear wall structure, and model 1 is frame structure, Under the same conditions, the lateral stiffness of shear wall structure is better than the lateral stiffness of frame structure, so Max-(X) and Max-(Y) of the same floor in model 2 are less than Max-(X) and Max-(Y) of the same floor in model 1. Max-Dx and Max-Dy of both models are gradually increasing trend firstly with the increase of floors, then are gradually decreasing trend from the middle floor to the top floor. The phenomenon demonstrates that the horizontal wind load affects the interlayer displacement at the bottom of structure greatly, but the interlayer displacement is affected by the horizontal wind load littlely. Max-Dx/h is maximum interlayer displacement angle which is the important index parameter measuring interlayer rigidity. Maximum interlayer displacement of floor and maximum interlayer displacement angle of the layers are both few, 
and both meet the regulation of elastic interlayer displacement angle of structures which is " $\theta \leq[\theta \mathrm{e}]=$ 1/500". Ratio-AX and Ratio-AY of models are both few, and both meet the relevant regulatory requirements.

In table 5, the lateral stiffness of model 1 is fewer than the lateral stiffness of model 2 , and model 1 is softer than model 2. So the pulsation increasing coefficient of model 1 is more than the pulsation increasing coefficient of model 2. Similarly, under the wind load, the acceleration acting on the soft structure is more than the acceleration acting on the hard structure, so the wind acceleration of model 1 is more than the wind acceleration of model 2. The comfort of model 2 is better than the comfort of model 1.

\section{Conclusions}

In summary, according to numerical simulation analysis on displacement response of frame structure and shear wall structure under the action of wind load, we can conclude that the lateral stiffness of rigid structure is more than the lateral stiffness of flexible structure, the lateral stiffness of shear wall structure is better than the lateral stiffness of frame structure. However, all the building structure are not adopted shear wall structure, the way is too one-sided, and we can not treat as the same. Construction units and design units should select suitable building structure type according to structure type, structural properties, number of floors, floor height, seismic conditions, wind conditions, construction technology, project costs, geological conditions, etc. In the right condition, frame structure is improved by setting shear walls to change into frame shear wall structure, the performance of frame shear wall structure is between frame structure and shear wall structure, and frame shear wall structure is widely used in 8 15 stories residential building structure.

\section{Acknowledgements}

This research was financially supported by the 2015 Research Project of Chengdu Textile College (Grant No.2015fzlkc06). Corresponding author is Chen Gong.

\section{References}

[1] Long Yuqiu, Bao Shihua, Yuan Si, Structural Mechanicsl , Beijing, Higher Education Press.

[2] Long Yuqiu, Bao Shihua, Yuan Si, Structural Mechanicsll , Beijing, Higher Education Press.

[3] MOHURD, Load code for the design of building structures, Peking, China Architecture and Building Press, 2012.

[4] MOHURD, Code for design of concrete structures, Peking, China Architecture and Building Press, 2010.

[5] Chen Gong, Xian Jinhong. Calculation Analysis And Application Of Shear Wall In The High-Rise Building Seismic, Science Technology and Engineering, 2013. 